\title{
Photobiomodulation as a treatment for dermatitis caused by chemoradiotherapy for squamous cell anal carcinoma: case report and literature review
}

\author{
Fabiana Hottz ${ }^{1 *}\left(\mathbb{0}\right.$, Daniel Herchenhorn ${ }^{1,2}$, Juliana Lenzi ${ }^{3}$, Juliana Andrade ${ }^{4}$, Vinicius Freire ${ }^{4}$ and Pedro Pinho ${ }^{5}$
}

\begin{abstract}
In-field dermatitis is a severe and common adverse effect of radiation therapy, that can cause significant pain and treatment interruptions in patients with squamous cell anal carcinoma (SCAC) being treated with radical chemoradiation protocols. There are no established therapies for the treatment of radiation induced dermatitis. Photobiomodulation (PBM) is an effective and low-cost treatment for radiation induced mucositis, but have recently been explored to treat in-field dermatitis. We present a case report of the successful use of PBM for the treatment of dermatitis in the anal area in a patient with SCAC treated with concomitant chemoradiation with curative intent and follow with a literature review of the recent advances and possibilities of the use of PBM as a promising strategy. PBM therapy proved to be efficient in the radiodermatitis treatment, both in relieving the symptoms and controlling dermatitis, in addition to improving the patient's quality of life.
\end{abstract}

Keywords: Anal cancer, Radiotherapy, Laser therapy, Radiodermatitis

\section{Introduction}

Squamous cell anal carcinoma (SCAC) is considered a rare tumor type. The Human papillomavirus infection (HPV infection) is the major risk factor, especially the HPV subtype 16. Currently, the first-line treatment with curative intent consists of chemotherapy $(\mathrm{CT})$ and radiation therapy (RT) combined, followed by perineal surgery only as a salvage therapy in case of relapse or residual tumors [1-3].

The intensity-modulated radiation therapy (IMRT) is the chosen radiation therapy type for treating cancer of the anal canal due to its advanced technology that reduces exposure of healthy tissues to radiation,

*Correspondence: fabianahottz@yahoo.com.br

1 Department of Physiotherapy, Oncologia D'Or, Rio de Janeiro, Brazil

Full list of author information is available at the end of the article preserving the patient's bladder, intestine and sexual function [4-6].

Despite technological advances there are still significant side effects that can cause morbidity and interfere with treatment, causing pain and also treatment interruptions, such as in-field dermatitis. Singh and cols. demonstrated the frequency of dermatitis in patients undergoing RT in the breast which may affect as much as $95 \%$ of the patients. The intensity varies from mild erythema to dry or wet desquamation, which can affect the quality of life and cause treatment delays [8].

Radiation induced dermatitis derives to the fact that the target is closer to the skin and receives a high radiation dose [9].

Total radiation dose, dose fractionation scheme, type of external beam used, radiosensitivity, concomitant chemotherapy, volume and area to be treated can be associated risk factors [7]. original author(s) and the source, provide a link to the Creative Commons licence, and indicate if changes were made. The images or other third party material in this article are included in the article's Creative Commons licence, unless indicated otherwise in a credit line to the material. If material is not included in the article's Creative Commons licence and your intended use is not permitted by statutory regulation or exceeds the permitted use, you will need to obtain permission directly from the copyright holder. To view a copy of this licence, visit http://creativecommons.org/licenses/by/4.0/. The Creative Commons Public Domain Dedication waiver (http://creativeco mmons.org/publicdomain/zero/1.0/) applies to the data made available in this article, unless otherwise stated in a credit line to the data. 
Acute radiodermatitis in anal canal cancer is considered to be highly prevalent, occurs in $99.1 \%$. Severe acute radiodermatitis cancer of the anal canal has an incidence rate of approximately $34.5 \%$ and may lead to treatment interruption [10, 11].

Treatment of radiodermatitis is not well established. Skin care should be advised to prevent injury and infection from reaching a greater grade $[12,13]$.

PBM, is a treatment already mentioned in studies for preventing and controlling radiodermatitis in patients undergoing RT for breast cancer is PBM, which is appeared safe, non-invasive, low-cost resource, having already been widely used in head and neck tumors to prevent mucositis, morbidity that impairs functionality and negatively impacts quality of life, in addition to increasing treatment costs [14-16].

Prevention of OM in patients undergoing RT for head and neck tumors suggest that PBM does not interfere with the tumor or the results of treatment and overall survival $[17,18]$.

This study presents a case of PBM application related to radiotherapy in a patient undergoing combined chemoradiotherapy for squamous cell anal canal carcinoma and it also reviews previous studies using this therapy as treatment and/or prevention of skin reactions caused by radiotherapy.

\section{Case report}

A 62-year-old man, presented a lesion in the anal and perianal region, followed by weight loss, tenesmus, urgency and discrete fecal incontinence, and was diagnosed with cancer of anus and anal canal, identified as invasive squamous cell carcinoma (SCAC) in October 2019. After a magnetic resonance imaging (MRI) of the abdomen and pelvis, in addition to computed tomography of the chest, he was staged II.

The patient underwent treatment with capecitabine at a dose of $850 \mathrm{mg} / \mathrm{m}^{2}$ bid during days of radiotherapy (tumor bed and drainage chains). The choice of capecitabine was due to his recent HIV diagnosis and the concomitant use of antiretroviral therapies. IMRT was performed in a total of 30 fractions, energy (photon beam), RapidArc ${ }^{\mathrm{TM}}$ technique, 6MV, $5400 \mathrm{cGy}$, totaling 05 weeks of treatment $(10 / 22 / 2019$ to $12 / 12 / 2019)$ to the anal lesion and pelvic nodes.

He was referred to physiotherapy before starting combined therapy. Upon examination, it was found the presence of an anal fistula and perianal tumor wound (Fig. 1) with no associated pain. On D18 of RT he presented with a grade 3 perianal radiodermatitis, according to the Radiation Therapy Oncology Group (RTOG) criteria, which was related to radiotherapy. He complained of burning pain in the anal mucosa when defecating, and there was an increase in defecatory frequency with a predominance of pasty to liquid stools, with a $6 / 7$ classification on the Bristol scale $[9,19]$.

PBM application with low-level laser (DMC EC POTENCIA brand; $100 \mathrm{MW}$, spot size $=0.03 \mathrm{~mm}$ ) was used, in red light length, with a dose of $2 \mathrm{~J}$ (joules) of energy in the irradiated perianal area and anal region twice a week-with an interval of $48 \mathrm{~h}$ between sessions for 4 weeks, until D7 after RT completion, which resulted in a relieve of pain and burning symptoms when defecating, evaluated by the visual analog scale (VAS) of pain from 9 to 3, and decrease of the radiodermatitis grade from 3 to 2 . The relief of the symptoms of radiodermatitis happened in the first application, in the seventh application (T7) of PBM, the patient referred VAS 3, and from eighty application (T8), asymptomatic.

Of note, patients using antiretroviral therapy seem to have greater toxicity to the treatment and may present greater toxicity on their skin and gastrointestinal when compared to patients not infected with HIV. Occasionally, they need to suspend or decrease radiotherapy dose $[20,21]$.

\section{Discussion}

Anal canal cancer is relatively rare. Radiation therapy is often the chosen modality for treating this disease. Radiodermatitis is one of the side effects of radiation therapy that can interfere with treatment adherence, and also a cause of serve pain and morbidity during and after therapy. It is a tissue inflammatory response that can progress to ulceration or tissue necrosis $[22,23]$.

In fact, Aragüés and colleagues suggest that acute radiodermatitis appears between 10 and 14 days after radiation therapy. However, radiodermatitis cases have been decreasing due to better treatment planning and the use IMRT. According to Han and collaborators, RD is considered the most common acute adverse effect of RT, with a frequency between $10 \%, 46 \%$ and $57 \%$ in anal and perianal cancer. In another retrospective study on breast cancer, the incidence of radiodermatitis was $81.19 \%$ and score 2 more prevalent $[24,25]$.

A prospective study, carried out by Kachnic et al. [26] evaluated the dose-painted intensity-modulated radiation therapy (DP-IMRT) method, in which it allows the allocation of different dose targets for the treatment, creating a different dose distribution for each location, as a result, Radiation Therapy Oncology Group (RTOG) 0529, showed shorter treatment interruption and significant savings in grade 3 acute dermatology toxicities (49\%) compared to RTOG 9811 (23\%), without using DP-IMRT, in addition to showing that $45 \%$ of patients discontinued treatment for acute dermatitis, of these, $88 \%$ duo to pain. 


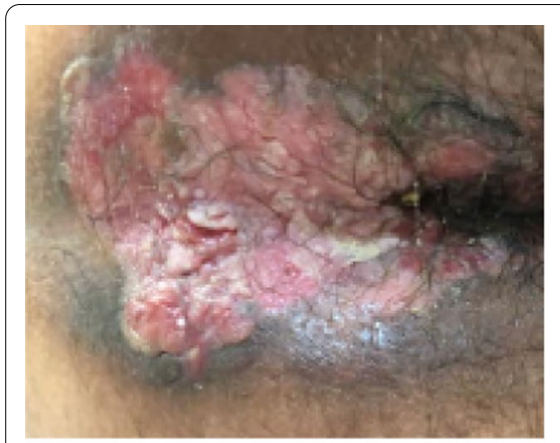

D1/RT

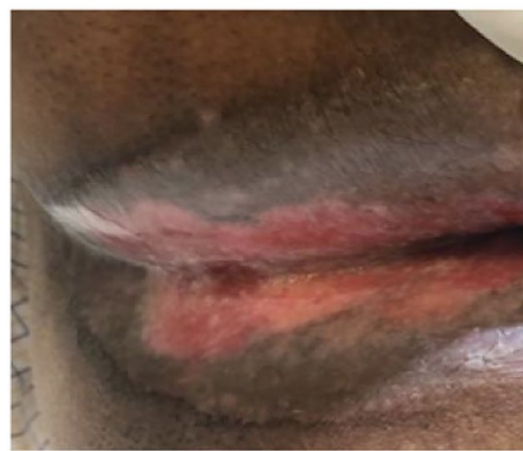

T8

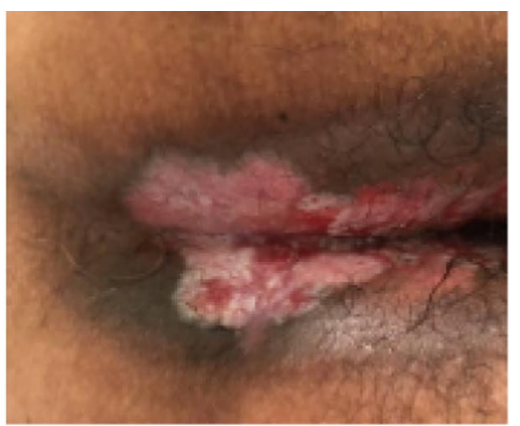

D18/RT T1

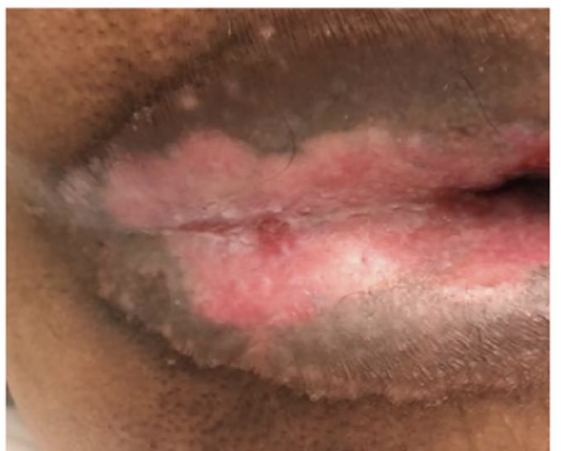

T9

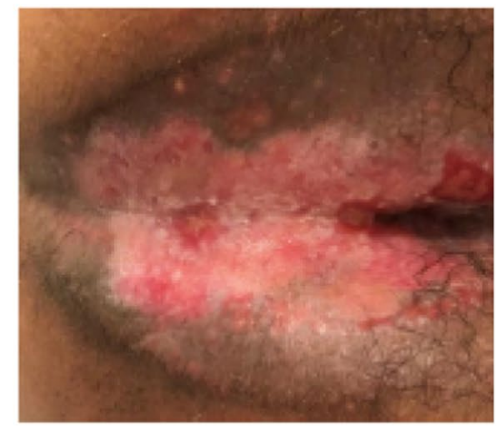

D30/RT T7

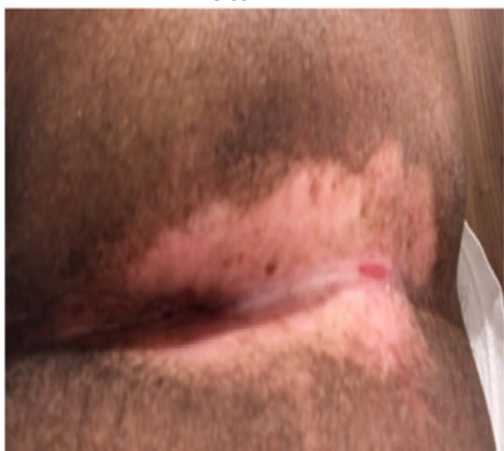

T

Fig. 1 Radiodermatitis (RD) in an 62-year-old man, diagnosed with cancer of anus and anal canal, identified as invasive squamous cell carcinoma (SCAC), stage II, in October. The patient referred weight loss, tenesmus, urgency and discrete fecal incontinence. D1-RT: First visit to the physiotherapy; tumor wound, wasn't performe the PBM. VAS = 0. D18-RT, T1: First PBM. VAS =9; tumor wound control; burning in the anal area; RTOG (grade III). D30-RT, T7: seventh PBM. Last day of the RT. VAS = 3; burning slight in the anal area; RTOG (grade III). T8: eighth PMB session five days after the end of radiotherapy. VAS =0; asymptomatic; RTOG (grade II/III). T9: ninth PBM session seven days after the end of radiotherapy. VAS $=0$; asymptomatic; RTOG (grade II). T: Follow-up one year after the end of PBM sessions. VAS =0; current; RTOG (grade 0)

Chronic radiodermatitis can appear approximately 90 days after radiotherapy and tissue repair chronification process induces fibrosis formation, and consequently, it can be followed by as pain, evacuating difficulty, pelvic dyssynergy and anal canal stenosis [2, 8].

Radiodermatitis development mechanism is largely linked to the inflammatory response associated with oxidative stress. Cellular damage induced by radiation, especially in the mitotic phase, triggers an inflammatory cascade that, when it becomes chronic associated with oxidative stress, leads to a modification of cytokines, alteration of the cell cycle and also promotes DNA damage. These changes support the inflammatory cascade, and consequently lead to disorderly tissue repair [27].

Currently, radiodermatitis treatment and prevention is based on polytherapies individualized to each service. Literature has shown effectiveness to mitigate radiodermatitis grade in breast cancer [28]. Robijins et al. [29] demonstrated that PBM can prevent acute radiodermatitis in patients with breast cancer submitted to RT. Additionally, that study, demonstrated that $12 \%$ of the patients in the treatment group had radiodermatitis grade 2 , while
$44.4 \%$ of the patients in the control group had radiodermatitis grade 2 or greater grades, concluding that the severity of skin reactions were significantly less in the group which PBM was performed, which means that this is an effective tool for preventing acute radiodermatitis, thus improving the quality of life of the patients.

In other study, the Dermishead trial, Robijins et al., Selected 46 head and neck cancer patients who underwent radiotherapy (RT) with or without concomitant chemotherapy to receive PBM or placebo treatment and investigate if PBM could be effective. As a result, $77.8 \%$ of the patients in the control group had grade $2-3$ radiodermatitis compared to $28.3 \%$ of the PBM. There was a $49 \%$ reduction in severe radiodermatitis in the PBM group. This randomized study demonstrated the effectiveness of PBM for the prevention and management of radiodermatitis.

There are only two reported cases of low-level laser application to treat radiodermatitis in the anal area. The first one described in the laser approach for chronic radiodermatitis and the second one was described for the treatment of radiodermatitis in rectal cancer during RT. 
In both cases there was a noticeable relieve in pain symptoms in the perianal region and tissue mucosa, allowing the patient to return to their daily activities [30].

A randomized prospective study evaluated patients with head and neck cancer and showed that the use of $\mathrm{PBM}$ to treat oral mucositis $(\mathrm{OM})$ was associated to a higher complete response rate to treatment. Patients who were followed for 40.3 months had a statistically greater complete response in the PBM group compared to the placebo group ( $89.1 \%$ vs. $67.4 \%)$, in addition to an increase in progression-free survival $(61.7 \%$ vs. $40.4 \%)$ and a tendency for better overall survival $(57.4 \%$ vs. 40.4\%). Patients who received PBM had a lower incidence of grade $3-4$ OM $(6.3 \%$ vs. $48 \%)$, thus, reduced gastrostomy, less interruption of treatment and use of opioids. In addition to having a positive impact on therapy adverse-events and a major impact on quality of life, positive results in response and survival reinforce the use of this therapy as part of the multidisciplinary approach for patients with head and neck cancer [31].

Radiodermatitis, in addition to severely affecting the patient's quality of life, can also cause a radiotherapy treatment interruption. Therefore, an effective approach is needed to treat and prevent this common effect.

PBM promotes tissue regeneration due its cellular and anti-inflammatory biomodulation action, relieving pain and promoting healing [32]. This case report reinforces the results of the aforementioned studies. The use of lowlevel laser with red light length is effective in the control of radiodermatitis.

Despite the limitations above, our approach was satisfactory, since there was a pain relief on the visual analog scale, tissue healing and reduction of radiodermatitis according to the classification of RTOG from grade 3 to grade 2 in the anal region in four weeks. PBM is an effective, safe and low-cost therapeutic resource and not interfere with therapy efficacy.

\section{Conclusion}

$\mathrm{PBM}$ in the anal region during RT treatment enabled symptom relief, radiodermatitis control and improved the patient's quality of life. In addition to being an innovative, safe and low-cost therapeutic option. We believe there is a need randomized clinical trials to better define the parameters and introduce this resource as a treatment protocol for radiodermatitis in the anal region.

\footnotetext{
Abbreviations

CT: Chemotherapy; DP-IMRT: Dose-painted intensity-modulated radiation therapy; HPV infection: Human papillomavirus infection; IMRT: Intensitymodulated radiation therapy; MRI: Magnetic resonance imaging; OM: Oral mucositis; PBM: Photobiomodulation; RT: Radiation therapy; RTOG: Radiation
}

Therapy Oncology Group; SCAC: Squamous cell anal carcinoma; VAS: Visual analog scale.

\section{Acknowledgements}

Not applicable.

\section{Authors' contributions}

All the authors have read and approved the final manuscript.

Funding

Not applicable.

Availability of supporting data

Department of Radiation Therapy, Oncologia D'Or, Rio de Janeiro, Brazil.

\section{Declarations}

Ethics approval and consent to participate

Not applicable.

\section{Consent for publication}

Consent for publication was obtained from the patient described in this article.

\section{Competing interests}

The authors declare that they have no competing interests.

\section{Author details}

${ }^{1}$ Department of Physiotherapy, Oncologia D'Or, Rio de Janeiro, Brazil. ${ }^{2}$ Instituto D'Or de Pesquisa e Ensino (IDOR), Rio de Janeiro, Brazil. ${ }^{3}$ Department of Physiotherapy, Pelvien Clinic, Campinas, Brazil. ${ }^{4}$ Department of Oncology, Oncologia D'Or, Rio de Janeiro, Brazil. ${ }^{5}$ Department of Radiation Oncology, Oncologia D'Or, Rio de Janeiro, Brazil.

Received: 19 December 2021 Accepted: 18 February 2022

Published online: 07 March 2022

\section{References}

1. Ghareeb A, Paramasevon K, Mokool P, et al. Toxicity and survival of anal cancer patients treated with intensity-modulated radiation therapy. Ann R Coll Surg Engl. 2019;101:168-75.

2. Oblak I, Petric P, Anderlub F, et al. Long-term outcome after combined modality treatment for anal cancer. Radiol Oncol. 2012;46(2):145-52.

3. Kronborg C, Serup-Hansen E, Lefevre A. Prospective evaluation of acute toxicity and patient reported outcomes in anal cancer and plan optimization. Anal Cancer. 2018;128(2):375-9.

4. Taylor A, Powell MEB. Intensity-modulated radiotherapy — what is it? Cancer Imaging. 2004;4:68-73.

5. De Francesco I, Thomas K, Wedlake L, Tait D. Intensity-modulated radiotherapy and anal cancer: clinical outcome and late toxicity assessment. Clin Oncol. 2016;28(9):604-10.

6. Castaneda SA, Romak LB. Radiotherapy for anal cancer intensitymodulated radiotherapy and future directions. Surg Oncol Clin N Am. 2017;26:467-75.

7. Singh $M$, et al. Radiodermatitis: a review of our current understanding Am J Clin Dermatol. 2016;17(3):277-92.

8. Ludmir EB, Kachnic LA, Czito BG. Evolution and management of treatment- related toxicity in anal cancer. Surg Oncol Clin N Am. 2017:26:91-113.

9. Robijns J, et al. Prevention of acute radiodermatitis by photobiomodulation: a randomized, placebo-controlled trial in breast cancer patients (TRANSDERMIS trial). Lasers Surg Med. 2018;50(7):763-71.

10. Han K, Cummings BJ, Lindsay P, et al. Prospective evaluation of acute toxicity and quality of life after IMRT and concurrent chemotherapy for anal canal and perianal cancer. Int J Radiat Oncol Biol Phys. 2014;90(3):587-94.

11. Bastos LJD. Prevalence of radiodermatitis in patients with anal canal cancer and rectum and risk factors associated with severe radiodermatitis. 
Rio de Janeiro, s.n., p. 34. https://pesquisa.bvsalud.org/portal/resource/ pt/biblio-1147982 (2019).

12. Haddad P, Amouzgar-Hashemi F, Samsami S, et al. Aloe Vera for prevention of radiation-induced dermatitis: a self-controlled clinical trial. Curr Oncol. 2013;20(4):345-8.

13. Fogh $\mathrm{S}$, Yom SS. Symptom management during the radiation oncology treatment course: a practical guide for the oncology clinician. Semin Oncol. 2014;41(6):764-75.

14. Antunes $\mathrm{HS}$, Schluckebier $\mathrm{LF}$, Herchenhorn D, et al. Cost- effectiveness of low-level laser therapy (LLLT) in head and neck cancer patients receiving concurrent chemoradiation. Oral Oncol. 2016;52:85-90.

15. Robijins J, Lodewijckx J, Bensadoun R-J, Mebis JA. Narrative review on the use of photobiomodulation therapy for the prevention and management of acute radiodermatitis: proposed mechanisms, current clinical outcomes, and preliminary guidance for clinical studies. Photomed Laser Surg. 2020;38(6):332-9.

16. Hamblin MR, Nelson ST, Strahan JR. Photobiomodulation and cancer: what is the truth? Photomed Laser Surg. 2018;20(20):1-5.

17. Genot-Klatersky MT, Paesmans M, Ameye L, et al. Retrospective evaluation of the safety of low-level laser therapy/photobiomodulation in patients with head/neck cancer. Support Care Cancer. 2020;27(7):3015-22.

18. Bensadoun R, Epstein JB, Nair RG. Safety and efficacy of photobiomodulation therapy in oncology: a systematic review. Cancer Med. 2020:9:8279-300.

19. Lin KY, Frawley HC, Denehy L, Feil D, Granger CL. Exercise intervention for patients with gynecological cancer: ma systematic review and metaanalysis. Physiotherapy. 2016;102:309-19.

20. Blazy A, Hennequin C, et al. Anal carcinomas in HIV-positive patients: high-dose chemoradiotherapy is feasible in the era of highly active antiretroviral therapy. Dis Colon Rectum. 2005;48:1176-81.

21. Berry JM, Palefsky JM, Welton ML. Anal cancer and its precursors in HIVpositive patients: perspectives and management. Surg Oncol Clin N Am. 2004;13:355-73.

22. Brown SR, Skinner P, Tidy J, et al. Outcome after surgical resection for high-grade anal intraepithelial neoplasia (Bowen's disease). Br J Surg. 1999;86(8):1063-6.

23. Chan RJ, et al. Prevention and treatment of acute radiation-induced skin reactions: a systematic review and meta-analysis of randomized controlled trials. BMC Cancer. 2014;14(1):1-19.

24. Aragüés IH, Perez AP, Fernandez RS. Inflammatory skin conditions associated with radiotherapy. Actas Dermosifiliogr. 2017;108(3):209-20.

25. Costa CC, Lyra JS, Nakamura RA, Souza CM. Radiodermatitis: analysis of predictive factors in breast cancer patients. Rev Bras Cancerol. 2019:65(1):275.

26. Kachnic LA, Winter K, Myerson RJ, et al. RTOG 0529: a phase II evaluation of dose-painted intensity modulated radiation therapy in combination with 5-fluorouracil and mitomycin- $\mathrm{C}$ for the reduction of acute morbidity in carcinoma of the anal canal. Int J Radiat Oncol Biol Phys. 2013;86(1):27-33.

27. Wei J, Meng L, Hou X, et al. Radiation-induced skin reactions: mechanism and treatment. Cancer Manag Res. 2019;11:167-77.

28. Wong RKS, Bensadoun R-J, Boers-Doets CB, Bryce J, Chan A, Epstein JB, et al. Clinical practice guidelines for the prevention and treatment of acute and late radiation reactions from the MASCC Skin Toxicity Study Group. Support Care Cancer. 2013;21:2933-48.

29. Robijns J, et al. Photobiomodulation therapy for the prevention of acute radiation dermatitis in head and neck cancer patients (DERMISHEAD trial). Radiother Oncol. 2021;158:268-75.

30. Gobbo M, Ottaviani G, Rupel K, Biasoto M. Can laser therapy be the answer for radiodermatitis in anal cancer patients? Two case reports. Photon Lasers Med. 2016;5(3):225-30.

31. Antunes HS, Herchenhorn D, Small IA, et al. Long-term survival of a randomized phase III trial of head and neck cancer patients receiving concurrent chemoradiation therapy with or without low-level laser therapy (LLLT) to prevent oral mucositis. Oral Oncol. 2017;71:11-5.

32. Migliario M, et al. Near infrared low-level laser therapy and cell proliferation: the emerging role of redox sensitive signal transduction pathways. J Biophotonics. 2018;11(11):1-7.

\section{Publisher's Note}

Springer Nature remains neutral with regard to jurisdictional claims in published maps and institutional affiliations.
Ready to submit your research? Choose BMC and benefit from:

- fast, convenient online submission

- thorough peer review by experienced researchers in your field

- rapid publication on acceptance

- support for research data, including large and complex data types

- gold Open Access which fosters wider collaboration and increased citations

- maximum visibility for your research: over 100M website views per year

At BMC, research is always in progress.

Learn more biomedcentral.com/submissions 